7-1-2015

\title{
Attitudes toward Death Anxiety and Dying Among Respiratory Therapy Students: A Pilot Study
}

Kevin Collins

Texas State University, kc35@txstate.edu

S. Gregory Marshall

Texas State University

Philip Vaughan

Texas State University

Follow this and additional works at: https://nsuworks.nova.edu/ijahsp

Part of the Other Medicine and Health Sciences Commons

\section{Recommended Citation}

Collins K, Marshall SG, Vaughan P. Attitudes toward Death Anxiety and Dying Among Respiratory Therapy Students: A Pilot Study. The Internet Journal of Allied Health Sciences and Practice. 2015 Jul 01;13(3), Article 5.

This Manuscript is brought to you for free and open access by the College of Health Care Sciences at NSUWorks. It has been accepted for inclusion in Internet Journal of Allied Health Sciences and Practice by an authorized editor of NSUWorks. For more information, please contact nsuworks@nova.edu. 


\title{
Attitudes toward Death Anxiety and Dying Among Respiratory Therapy Students: A Pilot Study
}

\begin{abstract}
Objective: To evaluate relative and absolute reliability and repeatability in assessing median nerve mobility at the level of the wrist and distal upper arm of the right upper extremity during wrist extension. Methods: Six healthy participants participated in the study. Median nerve mobility was captured three times at both sites using Sonocyte Turbo by two sonologists for a total of 72 video clips (36 for each site and 18 by each sonologist). Longitudinal movement was measured using Motion Tracking Analysis Program (MTAP) by the two assessors who were rehabilitation medicine residents. After one month, the assessors remeasured the longitudinal excursion of the median nerve of the previous video clips. Results: There was moderate agreement between the two sonologists of the median nerve mobility at the level of the distal upper arm and the wrist respectively. There was a moderate to almost perfect agreement between the two assessors' readings in the mobility of the nerve at level of the distal upper arm and wrist for the first and second readings. Repeatability testing showed that there was variable agreement at the level of the distal upper arm and at the wrist. Conclusion: MTAP using fast template tracking with an adaptive template is a reliable tool that can be employed in the accurate assessment of median nerve mobility at the distal upper arm and wrist.
\end{abstract}




\title{
TIAHSP \\ The Internet Joưnal of Allied Health Sciences and Practice \\ Dedicated to allied health professional practice and education
}

Vol. 13 No. 3 ISSN 1540-580X

\section{Attitudes toward Death Anxiety and Dying Among Respiratory Therapy Students: A Pilot Study}

\author{
Kevin Collins, MSc, RRT, RPFT, AE-C 1 \\ S. Gregory Marshall, PhD, RRT, RPSGT2 \\ Phillip Vaughan, $\mathrm{PhD}^{3}$
}

1. Assistant Professor, Department of Respiratory Care, Texas State University, San Marcos, Texas

2. Associate Professor, Department of Respiratory Care, Texas State University, San Marcos, Texas

3. Research Scientist, Research Support \& Evaluation Center, Texas State University, San Marcos, Texas

United States

\begin{abstract}
Purpose: This pilot study assessed respiratory therapy (RT) students' level of death anxiety at seven time points as measured by the revised Collett-Lester Fear of Death and Dying Scale (CL-FODS). The CL-FODS was administered as pre- and post-tests prior to the first clinical rotation and as a post-clinical assessment following each of five clinical rotations $(\mathrm{N}=32)$. Methodology: Respiratory therapy students were administered the CL-FODS pre-test prior to presentation of a didactic module on death and dying. Students were post-tested immediately following instruction. As clinical rotations were completed the following next five semesters, students were reassessed using the CL-FODS at the conclusion of each clinical rotation. The CL-FODS contains four categories asking students to assess their feelings of "Your Own Death," "Your Own Dying," "The Death of Others," and "The Dying of Others" using a 5-point Likert scale. The post-clinical instrument inquired whether the student had experienced a patient death and dying situation during the clinical rotation. Results: A repeated measures ANOVA and post-hoc analysis were utilized to analyze the data at an alpha level of 0.05 . ANOVA analysis of the mean differences between subjects from seven different time points was shown to be generally decreasing over time. Conclusion: The findings show first-year RT students reported lower death anxiety CL-FODS scores with continued clinical rotations in the acute care hospital setting.
\end{abstract}

\section{INTRODUCTION}

The impact of dealing with patient death and dying can have a profound effect upon healthcare providers in a personal way. For some healthcare providers, facing death and dying on a routine basis may produce personal death anxiety requiring the use of various coping mechanisms. Belsky has defined death anxiety as "the thoughts, fears, and emotions about that final event of living that we experience under more normal conditions of life." ${ }^{\text {D }}$ During the past two decades, a limited number of healthcare disciplines began expanding research related to death and dying and the impact upon the healthcare professional. The investigation of the attitudes toward death and dying among physicians, medical students, and nursing students are well represented in the literature. ${ }^{2-10} \mathrm{~A}$ study of respiratory therapy (RT) students and their attitudes toward death and dying could not be identified in the literature until the 2010 research of Stokes et al. ${ }^{11}$ Their research assessed 24-first year RT students measuring death anxiety utilizing the revised Collett-Lester Fear of Death and Dying Scale (CL-FODS) pre-, post lecture, and after one clinical rotation in an acute care hospital. ${ }^{12}$ The results of this study revealed there were no statistically significant differences between pre-, post-lecture, and post-clinical scores as measured by the CL-FODS instrument. The authors concluded a future study is warranted to capture additional information.

The introduction of the "stages of death and dying" by Kübler-Ross in 1986 resulted in a paradigm shift in the healthcare community regarding palliative care of patients and the impact of caring for the dying patient on healthcare professionals. ${ }^{13}$ Kübler-Ross purposed teaching healthcare professionals how to care for dying patients with an understanding of these stages would promote support of the patient and family in the midst of the emotional and physical changes preceding death. ${ }^{13}$ Preparing 
RT students for patient death and dying encounters can be extremely challenging. In addition to classroom and didactic information on the death and dying process, the impact of student clinical experiences of caring for patients in the midst of death and dying is significant. As all health professionals realize, the clinical experience of patients in death and dying situations can range from intervention that is aggressive and abrupt to palliative support with implemented comfort measures. RT students often find themselves suddenly submerged in a frenzy of life-saving activity, explosive patient or family emotions, or hushed and quieted circumstances. The question remains among some researchers as the personal impact of daily or weekly exposure to patient death and dying situations on healthcare professionals over an extended period of time.

A study by Campbell et al. suggests an individual's death attitudes may be developed prior to medical education, and in fact, a healthcare career may be chosen based on previously established death-related perspectives. ${ }^{14}$ Studies by Lattanner and Hayslip and Sundin et al suggest medical training, occupational experiences, and individual reaction to specific situations in the healthcare setting are responsible for developing the death-related attitudes of health professionals. ${ }^{15-16}$ The study of death anxiety and its impact on the healthcare provider is rooted in multiple psychological theories including search-for-meaning, selfrealization, denial and positive illusions, personal construct, terror management, and illusions of self-control theory. ${ }^{17-20}$ In the assessment of death anxiety, current research instruments have been constructed integrating multiple theoretical approaches in attempts to incorporate the multidimensionality of death anxiety theory within thanatology. ${ }^{21}$

Prior to 1969 , death anxiety inventories included items related to funerals and cemeteries and were not appropriate for properly assessing healthcare providers' death-related anxiety. The CL-FODS, developed by Collett and Lester, removed references to funerals, cemeteries, and crematoriums and focused on distinguishing death anxiety between death/dying. This approach of assessment resulted in four separate subscales: 1) Fear of Death of Self, 2) Fear of Death of Others, 3) Fear of Dying of Self, and 4) Fear of Dying of Others. Originally, the Collett-Lester instrument consisted of 36 statements with the request to rate each statement using a scale of +1 , slight agreement; +2 , moderate agreement; +3 , strong agreement; -1 , slight disagreement; -2 , moderate disagreement; -3 , strong disagreement. The original instrument demonstrated test-retest reliability, validity, and correlation; however, in order to improve the ease of use for administering and scoring, a revised Collett-Lester Scale was introduced in 1993 as a 5-point Likert scale.12,22,23 The revised Collett-Lester Likert scale was used to reflect the level of death anxiety associated with each of the thirty-two statements with 5 representing the highest level of death anxiety and 1 representing the lowest level of death anxiety. Studies reporting test-retest reliability, factor analyses, correlates for occupation, and correlates for illness and disease have confirmed validation of the revised CL-FODS in identifying death anxiety indicators using the new 32-item instrument with its 5-point Likert scale. ${ }^{12}$

The current study represents inclusion of an entire student cohort with assessments using the revised CL-FODS instrument (Appendix A) throughout the Bachelor of Science in Respiratory Care (BSRC) curriculum from the initial didactic lecture unit through five semester clinical rotations prior to completion of the 140-semester-hours degree. The five semesters of clinical education for this study represents a total of 880 clinical clock hours of the BSRC program's total 1200 clinical hours. The research question addressed by this study is, Will there be a change in the self-reported level of fear of death and dying experienced by RT students moving through the curriculum as measured by pre-, post-test, and post-clinical experience using the revised $\mathrm{CL}-\mathrm{FODS}$ ?

\section{METHODS}

Thirty-two, first-year students enrolled in the respiratory care baccalaureate degree program at Texas State University provided research consent as participants in this pilot study. The students were surveyed at seven different time points utilizing the revised CL-FODS to measure the self-reported level of death anxiety prior to instruction, following instruction, and following five clinical rotations over a twenty-one month period that exposed some of the students to a death and dying patient experience. Investigators received Institutional Review Board (IRB) approval as a Category 1 (ii) exempt research study. A consent form was developed and distributed according to standard IRB practices to the thirty-two student participants. Twenty- four of the 32 students were female. Eighteen students were between 18 and 21 years of age, eight students were between 22 and 25 years of age, one student was between 26 and 29 years of age, and five students were 30 years of age or older. Eight students selfidentified as Hispanic, 18 students self-identified as Caucasian (white), non-Hispanic, five self-identified as black, non-Hispanic, and one self-identified as American Indian or Alaskan native.

Instructional materials addressing death and dying in the respiratory care curriculum were developed from the Stanford Faculty Development Center's "End-Of-Life Care Curriculum for Medical Teachers" module and Dr. Elizabeth Kübler-Ross's book of patient interviews describing the process of death and dying. ${ }^{13,24}$ The death and dying instructional module presents the rationale for end-of-life training and includes US mortality statistics and a detailed descriptions of the common signs and symptoms during the last 48 hours before death. Class exercises include discussions relating to the symptoms of dyspnea, the five stages of death

(c) The Internet Journal of Allied Health Sciences and Practice, 2015 
and dying, patient spiritual concerns, and the role of the respiratory therapist with a patient and family in the midst of death and dying. All students completed an introductory pre-respiratory care didactic theory course in the previous semester and were presently enrolled in a respiratory care didactic theory course, a respiratory care introductory instrumentation course, and a respiratory care pre-clinical course conducted in a laboratory on campus. During the pre-lecture (time 1) and post-lecture (time 2) summer semester, none of the students were enrolled in hospital-based clinical courses. Subjects had no previous work experience in respiratory care and had no prior hospital clinical experience. All students were certified in basic life support prior to the first clinical rotation in the hospital.

The pre- and post-assessment consisted of the identical CL-FODS thirty-two test items with eight questions addressing "Your Own Death," eight questions addressing "Your Own Dying," eight questions addressing "The Death of Others," and eight questions addressing "The Dying of Others." The CL-FODS instructions ask the subject "How disturbed or made anxious are you by the following aspects of death and dying" followed by a 5-point Likert scale for responses to each of the thirty-two statements. The Likert scale was used to reflect the level of death anxiety associated with each of the thirty-two statements, with 5 representing the highest level of death anxiety and 1 representing the lowest level of death anxiety.

The post-clinical assessments (times 3-7) consisted of the identical thirty-two-statement CL-FODS instrument. Participants also responded to the question, "Did you have a patient death/dying experience in your clinical rotation?" Options provided on the assessment defining a "death/dying experience" ranged from providing comfort measures to a terminally ill patient to an emergent situation in which the student performed cardiopulmonary resuscitation measures. The post-clinical CL-FODS assessment was administered on campus at the end of each semester to all subjects at the same time following each of five hospital rotations: summer 2011, fall 2011, spring 2012, fall 2012, and spring 2013 semesters. The clinical rotations in this study accounted for approximately 880 contact hours at various acute care hospitals. The clinical course included standard respiratory therapy clinical training on the adult general medical and surgical floors, neonatal intensive care unit, pediatric intensive care unit, and adult intensive care unit. Some students were exposed to death/dying experiences in the emergency department during their clinical rotations. According to routine clinical education rotation practices, clinical instructors sought emergent educational experiences related to cardiopulmonary resuscitation and the withdrawal or withholding of life supporting interventions that occurred throughout the hospital for student experience and engagement. In addition, students were routinely exposed to endstage, terminally ill patients for whom it has been elected to not provide resuscitation efforts per advance directives.

During the initial assessment in the summer semester, students were instructed to provide their response to the revised CLFODS thirty-two item statements. All student responses were recorded on scanning answer forms. Following the administration of the pre-assessment, the death and dying teaching module was presented to all students in a lecture format. At the conclusion of the teaching module, the revised CL-FODS instrument was administered as a post-assessment and students recorded responses on the provided answer forms. As students moved into the clinical phase of their education, they were administered the thirty-two item CL-FODS post-clinical instrument at the end of each clinical rotation with the additional question inquiring whether the student had a patient death/dying experience during their clinical rotation. Students who confirmed they had participated in a death and dying experience completed an additional questionnaire (Appendix B) requesting information on the patient-type (i.e., neonatal, infant, pediatric, adolescent, adult) and subject demographics (i.e., age, gender, ethnicity), along with the four additional questions. Students were asked to provide a response of "Yes", "No", or "I don't know" to the following four questions; 1) I was present at the time of the death or dying event; however, I only observed the events and did not participate in performing cardiopulmonary resuscitation (CPR) on the patient, 2) I was present at the time of the death or dying event AND I participated in the event by performing CPR on the patient, 3) The patient involved in my Death or Dying experience survived the resuscitation event, 4) I was not present at the time of the death or dying event; however, I did hear of the death or dying event of my patient.

\section{RESULTS}

Because each participant's score on the CL-FODS at each measurement occasion was obtained by averaging the 32 items, the resulting scores were treated as interval data for analytic purposes ${ }^{25} \mathrm{~A}$ repeated measures ANOVA and post-hoc analysis were utilized to analyze the data at an alpha level of 0.05 . Thirty-two participants completed the questionnaire at times 1,2 , and 3 . Attrition and/or not completing the questionnaire reduced the sample size to 29 at time 4, 28 at time 5,25 at time 6 , and 25 at time 7. Twenty-four participants had complete data across all seven time points. Descriptive statistics for all available participants as well as the subsample of participants with complete data across all seven time points are shown in Table 1. Cronbach's alpha reliabilities for the thirty-two item measure were uniformly high across all time points, ranging from .93 to .96 . Figure 1 graphically depicts the CL-FODS means across the seven time points for the full subject sample available at each time point and the subsample with complete data at each time point.

(C) The Internet Journal of Allied Health Sciences and Practice, 2015 
Table 1. Descriptive statistics for full sample and subsample with complete data

\begin{tabular}{cccc|ccc}
\hline \hline time & $\mathrm{n}$ & mean & SD & $\mathrm{n}$ & mean & $\mathrm{SD}$ \\
\hline 1 (pre-test) & 32 & 3.25 & 0.64 & 24 & 3.18 & 0.55 \\
2 (post-test) & 32 & 3.23 & 0.67 & 24 & 3.14 & 0.54 \\
3 (clinic 1) & 32 & 3.09 & 0.75 & 24 & 3.00 & 0.68 \\
4 (clinic 2) & 29 & 3.23 & 0.72 & 24 & 3.12 & 0.63 \\
5 (clinic 3) & 28 & 2.98 & 0.75 & 24 & 2.85 & 0.71 \\
6 (clinic 4) & 25 & 2.96 & 0.70 & 24 & 2.90 & 0.63 \\
7 (clinic 5) & 25 & 2.85 & 0.66 & 24 & 2.86 & 0.68 \\
\hline
\end{tabular}

No statistically significant change occurred in outcome scores from pre- to post-lecture (i.e., from time 1 to time 2), paired samples $t=.30, d f=31, p=.76$. A repeated measures ANOVA was next applied in order to examine the overall pattern of change over time. Change over time was statistically significant with sphericity assumed $F(6,138)=5.01, p<.001$. While Mauchly's test of sphericity was statistically significant, $W=.14, p=.004$, the effect of time remained statistically significant at the .05 level when the Greenhouse-Geisser $(p=.002)$, Huynh-Felt $(p=.001)$, and lower-bound $(p=.035)$ corrections were applied. Both the linear and the sixth order polynomial contrasts over time were statistically significant ( $p=.004$ for both). Scores may therefore be regarded as generally decreasing over time, and doing so in an oscillating fashion. Inspection of sample means shows that the most notable decreases occur from time 2 (post-lecture) to time 3 (after beginning hospital rotations) and from time 4 to time 5 (during hospital rotations). At no time point was there a statistically significant difference in anxiety by gender.

Between time 2 measurement and time 3 measurement (i.e., from post-lecture to the end of the first hospital rotation) 16 of 32 participants reported experiencing a death/dying event. Subsequently, 17 of 29 participants, 18 of 28 participants, 17 of 25 participants, and 20 of 25 participants reported experiencing a death/dying event between time 3 and time 4 , time 4 and time 5 , time 5 and time 6 , and time 6 and time 7, respectively. For those 24 participants who were measured at all seven time points, two never experienced a death/dying event. One participant experienced an event during only one rotation, three experienced an event during two rotations, seven experienced an event during three rotations, seven experienced an event during four rotations, and four experienced a death/dying event during all five rotations (mean $=3.17$ rotations in which a death/dying event occurred, $\mathrm{SD} \pm 1.43$ ). The patient types representing the 88 total death/dying events include 1 neonate, 6 pediatrics, 4 adolescents and 77 adults.

In order to examine the null hypothesis that there would be no significant difference between the CL-FODS pre-test, post-test and post-clinical scores, two regressions were estimated. First, time 3 (i.e., clinic 1) scores were regressed on both time 2 (i.e., post-lecture) scores and a dummy variable indicating whether (1) or not (0) the participant had experienced an event during the first clinical rotation. Then, time 7 (i.e., clinic 5) scores were regressed on both time 2 scores and the total number of time intervals/clinical rotations in which a participant experienced a patient death/dying event. The time 2 scores were included in each of these regressions as a predictor to control for individual differences in pre-rotation scores. Results are shown in Table 2. While post-lecture scores were highly predictive of subsequent scores, death/dying experiences in neither case were predictive of these scores.

Table 2. Regressions of Fear of Death and Dying scores on experiences of death/dying events and previous scores

\begin{tabular}{|c|c|l|c|c|c|c|c|}
\hline outcome & $\mathbf{n}$ & \multicolumn{1}{|c|}{ predictor } & $\mathbf{B}$ & $\mathbf{S E}$ & Beta & $\boldsymbol{t}$ & $\boldsymbol{p}$ \\
\hline $\begin{array}{c}\text { time 3 score } \\
\text { (Clinic 1) }\end{array}$ & 32 & intercept & 0.02 & 0.36 & & 0.06 & 0.95 \\
\hline & & time 2 score & 0.96 & 0.11 & 0.86 & 8.91 & 0.00 \\
\hline $\begin{array}{c}\text { death/dying event (no } \\
=0, \text { yes = 1) }\end{array}$ & -0.06 & 0.14 & -0.04 & -0.39 & 0.70 \\
\hline (Clinic 5) & 24 & intercept & 0.53 & 0.69 & & 0.77 & 0.45 \\
\hline & time 2 score & 0.81 & 0.20 & 0.65 & 4.05 & 0.00 \\
\hline & $\begin{array}{l}\text { total rotations with a } \\
\text { death/dying } \\
\text { experience }\end{array}$ & -0.07 & 0.08 & -0.15 & -0.93 & 0.36 \\
\hline
\end{tabular}




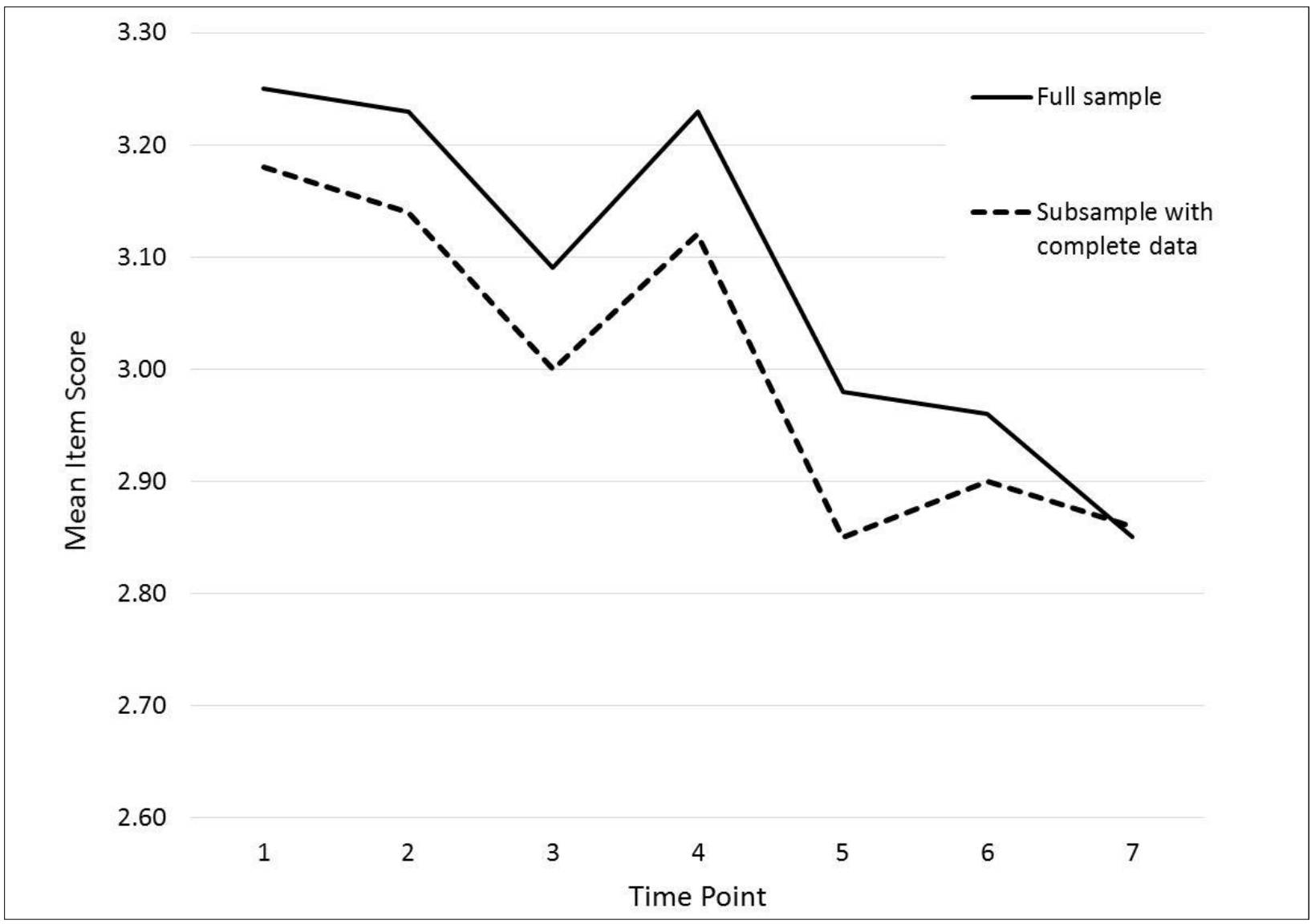

Figure 1. Scale means across seven time points (pre-lecture to clinic 5) for full sample available at each time point (full sample) and subsample with complete data at all-time points. Note. Possible range of $Y$-axis is from one to five.

\section{DISCUSSION}

The findings show first-year RT students reported less anxiety of patient death/dying issues with continued clinical rotations in the acute care hospital setting. The decrease in student self-reported death/dying anxiety was statistically significant over time. Results of the study reveal students did not have increased death anxiety scores with participation in a lecture of death/dying information as evidenced by pre-, post-lecture mean scores (Table 1). However, as students continued with clinical rotations, a decrease in death anxiety was noted with the most notable decreases in death anxiety scores occurring from time 2 (postlecture) to time 3 (after beginning hospital rotations) and from time 4 to time 5 (during hospital rotations). Additionally, death anxiety continued to decrease following subsequent hospital rotations with the greatest difference in means being between time 4 (clinic 2) and time 5 (clinic 3). Due to various potential influences in the subjects' independent experiences (e.g., exposure to the hospital environment, interaction with colleagues, or some other unknown factor), the exact cause of any increase or decrease in self-reported death anxiety scores among the students cannot be substantiated. For those 24 students who had data measured across all seven time points, $91.66 \%$ (22/24) experienced at least one death/dying experience during their clinical rotations with some students experiencing multiple death/dying experiences and two students never experiencing a death/dying experience. CL-FODS mean scores for the full sample of subjects and the subsample with complete data show a mirrored undulating, but declining death anxiety score for both sets of subjects (Figure 1).

The hypothesis was further tested through regression analysis. Two regressions were estimated, first, using the post-test time as the predictor with a variable indicating whether the student had experienced an event during the first clinical rotation and, second, using the total number of times students experience a patient death/dying event. The first regression model examines whether having a death/dying experience in the first rotation affected scores after this rotation, controlling for CL-FODS scores before this rotation. The second regression model examines whether the total number of death/dying experiences for a student throughout the study affected the student's CL-FODS score at the end of the study, while controlling for CL-FODS scores prior to any clinical rotation (Table 2). These findings suggest increased time in the acute care hospital setting may result in decreased death anxiety in respiratory therapy students. 
The CL-FODS is composed of four separate subscales, "your own death," "your own dying," "the death of others," and "the dying of others." Several analyses were performed to determine whether these subscales should be considered separately, rather than combined into a single score based on all 32 items. First, we performed the repeated measures analysis separately for each of the four subscales, including a detailed examination of the means for each subscale across the measurement occasions. We found that the pattern of change over time was not significantly different across the subscales. That is, the pattern of change over time that we report for the 32-item measure is essentially the same for each of the four smaller scales. Similarly, the regression results regarding the lack of impact of death/dying experiences did not change when subscales were considered individually. Finally, while our sample size does not permit a factor analysis of the responses to the CL-FODS, we manually examined correlations among items both within subscales and across subscales and found that in this sample, pairs of items from different CL-FODS subscales were approximately as strongly correlated as pairs of items within the same subscales. While not a formal analysis, this dovetails with our findings (above) of no changes in results across subscales and provides convergent evidence that using all 32 items together as single scale is reasonable in this particular context.

In a study by Brown-Saltzman et al conducted in the United States, the authors noted that practicing RTs encountered substantial experiences with end-of-life care, which resulted for some of the RTs in stress related to dealing with death and dying issues. ${ }^{26}$ In a Canadian study by Rocker et al, the authors studied the role of RTs in end-of-life care and their perspectives on death and dying. ${ }^{27}$ Rocker et al commented the role of RTs and their perspectives on end-of-life care is not well defined, suggesting further research is needed in this area. ${ }^{27}$ These two studies confirm the relevance of addressing death/dying issues with practicing RTs as well as respiratory therapy students. Even though these two particular citings involved practicing RTs as research participants and not RT students, death anxiety was not assessed using the CL-FODS instrument. A survey study by Willms and Brewer of RTs suggests that less than half of all RTs receive education about issues of patient death and dying. ${ }^{28}$ The lack of current literature on the topic of death anxiety among respiratory therapists suggests the need for future research in this area.

This study is limited in scope to students enrolled in a baccalaureate degree respiratory care program at a large public university in Texas. The convenient sample representation of our student population may provide limitations to study results when generalized for other student groups, higher education settings, academic disciplines, or clinical settings. Furthermore, a number of confounding variables may have inadvertently affected the outcomes of this study. Some students experienced multiple death/dying experiences while other students had no death/dying experiences, thereby possibly affecting their self-reported postclinical death anxiety scores. The elapse of time between the death/dying event and the measurement of student death anxiety scores may have affect post-clinical scores. Clinical experiences may vary from hospital to hospital. Permission for students to observe and participate in resuscitation events may vary between hospital sites. The impact of direct student participation as compared to observing resuscitation may affect post-clinical scores. Another limitation is the possibility of differing recent personal death-related events independent of the clinical experience, which may affect self-reported death anxiety scores. The authors acknowledge these variables are valid concerns and should be controlled providing the practicality and availability of clinical experiences for student learning. Future research might include a study comparing the effects of receiving didactic training on death and dying versus not receiving the training followed by clinical experiences. Similar studies in different geographical areas, educational settings, and clinical settings are warranted. In conclusion, findings of this study suggest the exposure of first-year RT students to death/dying didactic information and death/dying patient clinical situations does not lead to an increased death anxiety score; rather, students reported lower death anxiety CL-FODS scores with continued clinical rotations in the acute care hospital setting.

\section{REFERENCES}

1. Belsky J. The Psychology of Aging. Salt Lake City, UT: Brooks/Cole Publishing Co; 1999.[ISBN:0534359124]

2. Servaty HL, Krejci MJ, Hayslip, B. Relationships among death anxiety communication apprehension with the dying, and empathy in those seeking occupations as nurses and physicians. Death Stud. 1996;20:149-61.

3. Kvale J, Berg L, Groff JR, Lange G. Factors associated with residents' attitudes toward dying patients. Fam Med. 1999;31:691-6. [PMID:10572764]

4. Garfinkle CL, Block P. Physicians' interaction with families of terminally ill patients. Fam Med. 1996;28:702-7. [PMID:8937871]

5. Campbell TW, Abernethy V, Waterhouse GJ. Do death attitudes of nurses and physicians differ? Omega. 1983;14:439.

6. Powell FC, Thorson JA, Kara G, Uhl HS. Stability of medical students' attitudes toward aging and death. J Psychol. 1990;127:339-42.[PMID:2348413]

(C) The Internet Journal of Allied Health Sciences and Practice, 2015 
7. Thorson JA, Powell FC. Medical students' attitudes towards aging and death: A cross-sequential study. Med Educ. 1991;25:32-7.[PMID:1997826]

8. Waltman NL. Attitudes, subjective norms, and behavioral intentions of nurses toward dying patients and their families. Oncol Nurs Forum. 1990;17:55-62.[PMID:2342984]

9. Kincade JE. Attitudes of physicians, housestaff, and nurses on care for the terminally ill. Omega. 1983;13:33344.[PMID:11658380]

10. Miles MS. The effects of a course on death and grief on nurses' attitudes toward dying patients and death. Death Educ. 1980;4(3):245-60. [PMID:10248467]

11. Stokes TJ, Marshall SG, Russian CJ. Attitudes Toward Death Anxiety and Dying Among Respiratory Care Students: A Pilot Study. Respiratory Care Education Annual. 2010;19:43-55.

12. Lester D. The Collett-Lester Fear of Death Scale. Death Anxiety Handbook: Research, instrumentation, and application. Washington, DC: Taylor \& Francis; 1994:45-60.[ISBN-13:978-1560322825]

13. Kübler-Ross E. On Death and Dying. New York: Macmillan; 1986.[ISBN-13:978-0684839387]

14. Campbell TW, Abernethy V, Waterhouse GJ. Do death attitudes of nurses and physicians differ? Omega. 1983;14:43-9.

15. Lattanner B, Hayslip B. Occupational-related difference in levels of death anxiety. Omega. 1985;15:53-66.

16. Sundin R, Gaines WG, Knapp WB. Attitudes of dental and medical students toward death and dying. Omega. 1979; 10:77-86.

17. Templer DJ. The construction and validation of a Death Anxiety Scale. J Gen Psychol. 1970;82:165-77. [PMID:4394812]

18. Thorson JA, Powell FC. A Revised Death Anxiety Scale. In: Neimeyer RA, editor. Death Anxiety Handbook. Washington, DC: Taylor \& Francis; 1994:31-43.[ISBN-13:978-1560322825]

19. Krieger SR, Epting FR, Leitner LM. Personal constructs, treat, and attitudes toward death. Omega. 1979;5:299-310.

20. Hoelter JW. Multidimensional treatment of fear of death. J Consul Clin Psychol. 1979;47:996-9. [PMID:512155]

21. Tomer A. Death Anxiety in Adult Life-Theoretical Perspectives. In: Neimeyer RA, editor. Death Anxiety Handbook. Washington, DC: Taylor \& Francis; 1994:3-28.[ISBN-13:978-1560322825]

22. Lester D, Collett LJ. Fear of death and self-ideal discrepancy. Archiv Found Than. 1970;2:130.

23. Lester D, Abdel-Khalek A. The Collett-Lester Fear of Death Scale: A correction. Death Stud. 2003;27:81-5. [PMID:12508829]

24. Hallenbeck J, Katz S, Stratos G. End-of-Life Care Curriculum for Medical Teachers. Stanford Faculty Development Center; Stanford University School of Medicine. Palo Alto, CA: 2003.

25. Carifio J, Perla RJ. Ten Common Misunderstandings, Misconceptions, Persistent Myths and Urban Legends about Likert Scales and Likert Response Formats and their Antidotes. Journal of Social Sciences. 2007:3(3):106-16.

26. Brown-Satzman K, Upadhya D, Lamer, L, Wenger NS. An intervention to improve respiratory therapists' comfort with end-of-life-care. Respir Care. 2010;55(7):858-64.[PMID:20587097]

27. Rocker GM, Cook DJ, O'Callaghan CJ, Pichora D, Dodek PM, Conrad W, et al. Canadian nurses' and respiratory therapists' perspectives on withdrawal of life support in the intensive care unit. J Crit Care. 2005;20(1):5965.[PMID:16015517]

28. Willms DC, Brewer JA. Survey of respiratory therapists' attitudes and concerns regarding terminal extubation. Respir Care. 2005;50(8):1046-9. [PMID:16225709] 


\section{Appendix A}

\section{Revised Collett-Lester Fear of Death and Dying Scale}

How disturbed or made anxious are you by the following aspects of death and dying? Read each item and answer it quickly. Don't send too much time thinking about your response. We want your first impression of how you think right now. Please circle the number that best represents your feeling:

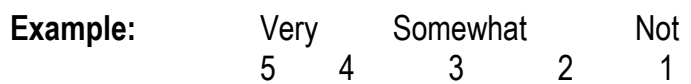

\section{Your Own Death}

1. The total isolation of death

2. The shortness of life

3. Missing out on so much after you die

4. Dying young

5. How it will feel to be dead

6. Never thinking or experiencing

7. The possibility of pain/punishment during life-after-death

8. The disintegration of your body after you die

\section{Your Own Dying}

9. The physical degeneration involved

10. The pain involved in dying

11. The intellectual degeneration of old age

12. That your abilities will be limited as you lie dying

13. The uncertainty as to how bravely you will face the process of dying

14. Your lack of control over the process of dying

15. The possibility of dying in a hospital away from friends and family

16. The grief of others as you lie dying

\section{The Death of Others}

17. Losing someone close to you

18. Having to see the person's dead body

19. Never being able to communicate with the person again

20. Regret over not being nicer to the person when he or she was alive

21. Growing old alone without the person

22. Feeling guilty that you are relieved that the person is dead

23. Feeling lonely without the person

24. Envious that the person is dead

\section{The Dying of Others}

25. Having to be with someone who is dying

26. Having the person want to talk about death with you

27. Watching the person suffer from pain

28. Having to be the one to tell the person that he or she is dying

29. Seeing the physical degeneration of the person's body

30. Not knowing what to do about your grief at losing the person when you are with him or her

31. Watching the deterioration of the person's mental abilities

32. Being reminded that you are going to go through the experience also one day 


\section{Appendix B}

\section{Texas State University-San Marcos \\ Department of Respiratory Care Death \& Dying Additional Questions}

1. Did you have a patient death/dying experience in your clinical rotation?

$\square$ Yes $\quad \square$ No

2. Which patient group represents your patient for the death or dying circumstance that you experienced? Please mark the appropriate box for your patient.
$\square$ Neonate
$\square$ Infant
$\square$ Pediatric
$\square$ Adolescent
$\square$ Adult

Please answer ALL of the following questions:

3. I was present at the time of the death or dying event; however, I only observed the events and did not participate in performing CPR on the patient

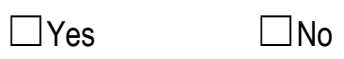

4. I was present at the time of the death or dying event AND I participated in the event by performing CPR on the patient.

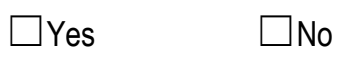

5. The patient involved in my Death or Dying experience survived the resuscitation event?
$\square$ Yes
$\square$ No
I don't know

6. I was not present at the time of the death or dying event; however, I did hear of the death or dying event of my patient.

$\square$ Yes $\quad \square$ No

Subject \#

Survey 